\title{
The contribution of reduction in malaria as a cause of rapid decline of under-five mortality: evidence from the Rufiji Health and Demographic Surveillance System (HDSS) in rural Tanzania
}

\author{
Almamy M Kanté ${ }^{1,2^{*}}$, Rose Nathan² ${ }^{2}$ Stéphane Helleringer ${ }^{1}$, Mrema Sigilbert ${ }^{2}$, Francis Levira ${ }^{2}$, Honorati Masanja $^{2}$, \\ Don de Savigny ${ }^{3}$, Salim Abdulla ${ }^{2}$ and James F Phillips ${ }^{1}$
}

\begin{abstract}
Background: Under-five mortality has been declining rapidly in a number of sub-Saharan African settings. Malaria-related mortality is known to be a major component of childhood causes of death and malaria remains a major focus of health interventions. The paper explored the contribution of malaria relative to other specific causes of under-five deaths to these trends.

Methods: This paper uses longitudinal demographic surveillance data to examine trends and causes of death of under-five mortality in Rufiji, whose population has been followed for over nine years (1999-2007). Causes of death, determined by the verbal autopsy technique, are analysed with Arriaga's decomposition method to assess the contribution of declining malaria-related mortality relative to other causes of death as explaining a rapid decline in overall childhood mortality.

Results: Over the 1999-2007 period, under-five mortality rate in Rufiji declined by 54.3\%, from 33.3 to 15.2 per 1,000 person-years. If this trend is sustained, Rufiji will be a locality that achieves MDG4 target. Although hypotrophy at birth remained the leading cause of death for neonates, malaria remains as the leading cause of death for post-neonates followed by pneumonia. However, declines in malaria death rates accounted for $49.9 \%$ of the observed under-five mortality decline while all perinatal causes accounted for only $19.9 \%$.
\end{abstract}

Conclusion: To achieve MDG 4 in malaria endemic settings, health programmes should continue efforts to reduce malaria mortality and more efforts are also needed to improve newborn survival.

Keywords: Under-five mortality, Malaria, Health and demographic surveillance system, Africa, Tanzania, Millennium development goal

\section{Background}

The fourth Millennium Development Goal (MDG4) aims to achieve a two-thirds reduction in under-five mortality rate (U5MR) during 1990-2015 [1]. Between 1990 and 2010, the average U5MR in the world has fallen by only one-third from 89 to 60 deaths per 1,000 live births [2]. In 2011, 7.2 million children under-five died in the world with

\footnotetext{
* Correspondence: amk2213@columbia.edu

'Mailman School of Public Health, Columbia University, 60 Haven Avenue, New York 10032, USA

${ }^{2}$ Ifakara Health Institute, PO Box 78373, Dar-Es-Salaam, Tanzania

Full list of author information is available at the end of the article
}

most of these deaths occurring in developing countries [3], of the regions of the world where achieving MDG4 has been most challenging, malaria has been a prominent cause of death. Yet, noteworthy progress has been registered in recent years. According to the Demographic and Health Surveys (DHS), the U5MR is declining in sub-Saharan Africa since 2000 after a decade of stagnation. Successive Tanzania DHS results have shown a decline of $40 \%$ of U5MR between 1992-1996 and 2006-2010 (from 137 to 81 per 1,000), with concomitant reduction in inequalities between age group, residence, maternal education and 
wealth quintile [4-7]. At the same time, U5MR declined faster in rural Tanzania than urban areas, from 85/ 1,000 to $60 / 1,000$ against $73 / 1,000$ to $63 / 1,000$, respectively. Inequality in progress is nonetheless evident by age at death: post-neonatal mortality declined from $41 / 1,000$ in 2001-2005 to 25/1,000 in 2006-2010 while neonatal mortality declined by only $30 / 1,000$ to $26 /$ 1,000 in the corresponding period.

While malaria-related mortality is known to represent a major component of childhood causes of death in Tanzania, and malaria remains a major focus of health interventions, the possible contribution to malaria reduction in the Tanzania's childhood mortality decline has yet to be investigated. This paper addresses this evidence gap. Improving scientific knowledge of childhood mortality trends is essential to guide efforts to prioritizing interventions and gauging the effectiveness of disease specific interventions [8-11]. In most developing countries however, there is a lack of precise data on demographic levels and trends because civil registration is incomplete. DHS in sub-Saharan Africa partially compensate for these gaps, but do not provide specific causes of death for children under-five years of age. Health and Demographic Surveillance systems (HDSS), a continuous monitoring of population in a delimited area, provide accurate information on mortality, fertility and migration trends [12]. The Rufiji HDSS (RHDSS), established in 1998 in a rural district of Pwani (Coast) Region, has collected data on causes of death by using the verbal autopsy (VA) study $[13,14]$. This paper analyses the contribution of malaria relative to other causes of death as components of the rapid U5MR decline in a rural district of coastal Tanzania.

\section{Methods}

\section{Data collection}

The RHDSS is located in Rufiji District about $178 \mathrm{~km}$ south of Dar es Salaam in eastern Tanzania between latitudes $7^{\circ} 47^{\prime}$ and $8^{\circ} 03^{\prime}$ South and longitudes $38^{\circ} 62^{\prime}$ and $39^{\circ} 17^{\prime}$ East. The RHDSS includes 38 of 94 villages of the district. Between 1999 and 2010, the monthly average temperature varied between 27.9 and $43.4^{\circ} \mathrm{C}$ and monthly rainfull between 0 and $420.7 \mathrm{~mm}$ [15].

In December 2007, the population under surveillance was 82,138 ( $47 \%$ of the district) and $15 \%$ were children under-five years old. The RHDSS area has a total of 18 health facilities (one hospital, two health centres and 15 dispensaries) and nearly $90 \%$ of the population lives within $5 \mathrm{~km}$ of a formal health facility [16].

Launched in November 1998 with a baseline census of the surveillance population, the RHDSS has since been updated in 120 day intervals by revisits of interviewers who register the occurrence of all births, deaths, household in and out migrations, and marital status changes. To ensure completeness in reporting births and deaths of newborns, pregnancies are also documented and outcomes are solicited in subsequent household visits (Figure 1).

The causes of deaths were determined by the VA techniques. Deaths that occurred during interviewing rounds are recorded and specially-trained field researchers revisit the decedent's home after a grieving period to conduct the interview. The VA forms are then independently reviewed by two physicians according to a list of causes of death based on the $10^{\text {th }}$ revision of the International Classification of Diseases [17]. A third physician codes the cause of death in case of discordant results. If there is disagreement among the three physicians, the death is coded as having an "undetermined" cause.

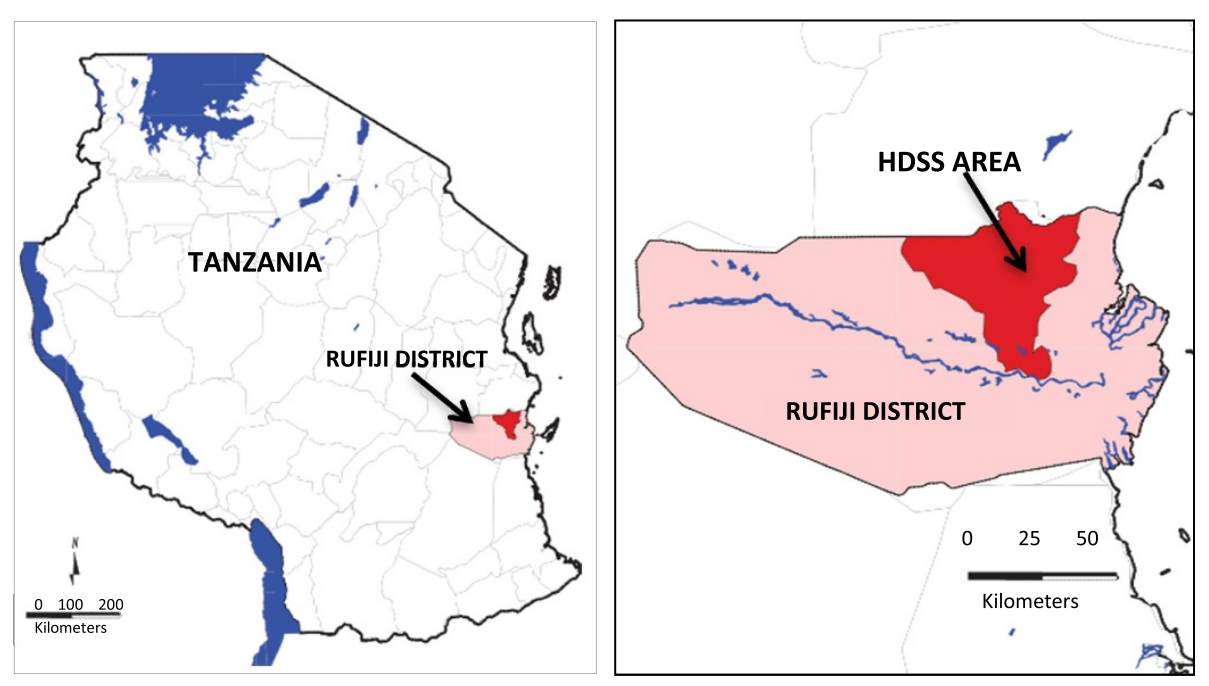

Figure 1 Map of the Rufiji Health and Demographic Surveillance System (RHDSS), Tanzania. 
Based on these data, it is known that more than $95 \%$ of women attend at least at one antenatal visit, $65 \%$ deliver at a health facility and $80 \%$ of births are assisted by health professionals. Immunization coverage ranges from $85 \%$ for the Bacillus Calmette-Guerin (BCG; tuberculosis) to $66 \%$ for measles among children 12 to 23 months of age. Coverage rates for any nets were around $60 \%$ in 2010 . The population covered by the RHDSS and in general the Pwani region, has better maternal health indicators, but worse child health indicators than circumstances prevailing elsewhere in rural Tanzania [7,13-16,18].

\section{Data analysis}

The RHDSS data compiled over the January 1999 to December 2007 period, are used to calculate successive annual under age five mortality rates (per 1,000 person-years in observation, PYO). During this period, 2,691 childhood deaths were recorded and the main causes of deaths were reviewed using the VA method. About 20.8\% of these deaths were reported as having undetermined causes and $5.7 \%$ were also not coded indicating the VA interviewer could not locate an appropriate respondent. Finally, 26.5\% of under-five deaths were unknown causes.

While the frequency of unknown causes is high, evidence suggests that the age and sex composition of deceased children with known causes is similar to the corresponding composition of characteristics of deceased children with unknown causes for each year in which HDSS data were compiled. Chi-square tests are used to gauge percent differences of between known and unknown causes by demographic characteristic of deceases, season and period of death. Moreover, most of these characteristics exhibit similar patterns. For example, $74.0 \%$ of causes of death among boys were known compared to $73.0 \%$ among girls $(\mathrm{p}=0.65)$. Also, $27.7 \%$ of deaths occurring during the raining season were unknow compared to $25.4 \%$ of deaths occuring during the dry season $(p=0.18)$. Maternal age data for children who died were also comparable $(p>0.05)$. Significant differences have however been noted for the age-group of children and the period of deaths. Twenty-three percent of neonatal death (less than one month of age) were unknown compared to $27.5 \%$ of postneonatal deaths (1-11 months) and $27.6 \%$ of post-infant deaths (12-59 months) $(\mathrm{p}=0.05)$ (Table 1$)$.

Analysts have used contrasting approaches to accounting for unknown causes in the analysis of mortality. Black et al. [9] and Hope et al. [10] exclude unknown causes from their analyses, an approach that affects estimates of the mortality level and the pace of trends. Liu [19] and Narh-Bana et al. [20] retain such data in their analyses as an "unknown category" representing a residual class. Waltisperger and Meslé [21], Naghavi et al. [22] and Abdullah et al. [23] have taken into account the unknown causes by redistributing at random by age group and sex the unknown causes of death among the known causes in order to assure the comparability of series over the study period. This method avoids modification of the cause of death structure from known causes, preserving as a result, representativeness of known causes of deaths. This paper used proportional redistribution method of unknow causes into the known causes in order to minimize information loss.

The rate for each cause of death has been calculated, defined by the number of deaths due to the cause $x$ occurring in a given period of time $t$, divided by the total number of person-years in observation (in per 1,000 PYO). Chi-square tests are also used to gauge differences of rates due to a cause $x$ between two periods $\left(t_{0}, t_{1}\right)$. The statistical significance is defined as a $p$-value $<0.05$.

To assess the proportionate contribution of each cause of death to the total change in life expectancy between $t_{0}$ and $t_{1}$, Chiang's method has been used for constructing life tables to calculate life expectancy [24], then a decomposition technique proposed by Arriaga [25] has been employed, which permits examination of the contribution of each cause of death by periods. This method assumes that within the underfive age group, the contribution that a cause of death makes to a change in life expectancy between $t_{0}$ and $t_{1}$ is proportional to contribution that this cause makes to the change in the central mortality rate in that age group. The overall difference in the life expectancy between birth and age-five has been calculated between $t_{0}$ and $t_{1}$. Then the difference has been decomposed in

Table 1 Repartition of known and unknown under-five causes of deaths by characteristics of children, mothers, period and season of death in the Rufiji Health and Demographic Surveillance System (RHDSS), Tanzania, 1999-2007

\begin{tabular}{|c|c|c|c|c|c|c|c|c|c|c|c|c|}
\hline \multirow{2}{*}{$\begin{array}{l}\text { Cause of } \\
\text { death }\end{array}$} & \multicolumn{2}{|c|}{ Sex } & \multicolumn{3}{|c|}{ Age group of child (month) } & \multicolumn{2}{|c|}{ Season of death } & \multicolumn{2}{|c|}{ Period of death } & \multicolumn{3}{|c|}{ Age group of mother (year) } \\
\hline & Boy & Girl & $<1$ & 1_11 & $12 \_59$ & Dry & Rain & $1999-2002$ & 2003-2007 & $<20$ & $20-30$ & $>30$ \\
\hline Known & 74.0 & 73.0 & 76.8 & 72.5 & 72.4 & 74.6 & 72.3 & 76.6 & 70.2 & 71.9 & 73.5 & 74.8 \\
\hline Unknown & 26.0 & 27.0 & 23.2 & 27.5 & 27.6 & 25.4 & 27.7 & 23.4 & 29.8 & 28.1 & 26.5 & 25.2 \\
\hline Total & 100.0 & 100.0 & 100.0 & 100.0 & 100.0 & 100.0 & 100.0 & 100.0 & 100.0 & 100.0 & 100.0 & 100.0 \\
\hline N & 1,395 & 1,296 & 643 & 1,033 & 1,015 & 1,372 & 1,319 & 1,399 & 1,292 & 683 & 1,186 & 822 \\
\hline
\end{tabular}

Significant at $\mathrm{p}<0.05$ level (in bold) (two-sided chi-square test). 
proportional contribution of each cause of death into the overall decline of U5MR. Statistical analyses were executed using Stata 12 [26] and Microsoft Excel (2010).

This paper combined malaria and fever (acute febrile illness) (presumptive malaria) because during the early stage of the study (1999-2002), 27.4\% of children deaths were attributed to fever without cough or respiratory distress, while that percent dropped to only $3.4 \%$ in the late stage (2003-2007). At the same time, the percent of children deaths attributed to malaria has increased from 6.7 to $25.9 \%$.

\section{Ethical approval}

Ethical approval was obtained from the Ministry of Health and Social Welfare, the National Medical Research Coordination Committee of National Institute for Medical Research and the Ifakara Health Institute (IHI)'s Institutional Review Board (IRB), Tanzania. Written informed consent was obtained from the patient's guardian/parent/next of kin for the publication of this report and any accompanying images.

\section{Results}

\section{Level and trends of under-five mortality rates}

The U5MR significantly declined by $54.3 \%$ in nine years from 33.3 per 1,000 person-years in observation (PYO) in 1999 to $15.2 / 1,000$ in 2007 . To ensure the comparability of trends, two periods have been considered: 1999-2002 during which the mortality level was high at $28,1 / 1,000$, then
2003-2007 during which mortality declined precipitously at $18.6 / 1,000(p<0.0001)$ (Figure 2).

\section{Cause of death of children under-five}

The main causes of death of children under-five recorded in the RHDSS were malaria and fever (presumptive malaria), acute respiratory infections (pneumonia in particular), diarrhoeal diseases, malnutrition, birth injuries and asphyxia (BIA), prematurity and low birth weight (PLBW), congenital abnormalities and other perinatal causes (sepsis, neonatal tetanus).

Between 1999-2002 and 2003-2007, the overall underfive mortality rates have significantly declined by one-third $(p<0.0001)$. Presumptive malaria mortality rate declined significantly from 12.5 to $7.8 / 1,000(p<0.0001)$, pneumonia from 4.0 to $2.8 / 1,000(p<0.001)$ and also malnutrition, diarrhoeal diseases, congenital abnormalities and other perinatal causes $(p<0.001)$. However, anaemia has increased from 0.9 to $1.6 / 1,000(p<0.001)$ and BIA from 1.2 to $1.5 / 1,000(p=0.15)$ (Table 2$)$.

As a consequence of the improved survival situation from 1999-2002 and 2003-2007, the life expectancy between birth and age-five in Rufiji increased from 4.55 to 4.70 years corresponding to 1.73 months. Contribution of each cause of death to extending life expectancy is represented here by proportionate contributions into overall decrease of U5MR (Table 3).

The difference in U5MR is of 9.5/1,000 $(28.1 / 1,000$ against 18.6/1,000) between 1999-2002 and 2003-2007 comes from a combined death rates difference of presumptive malaria, pneumonia, diarrhoeal diseases, malnutrition, BIA, etc. The proportionate contribution by

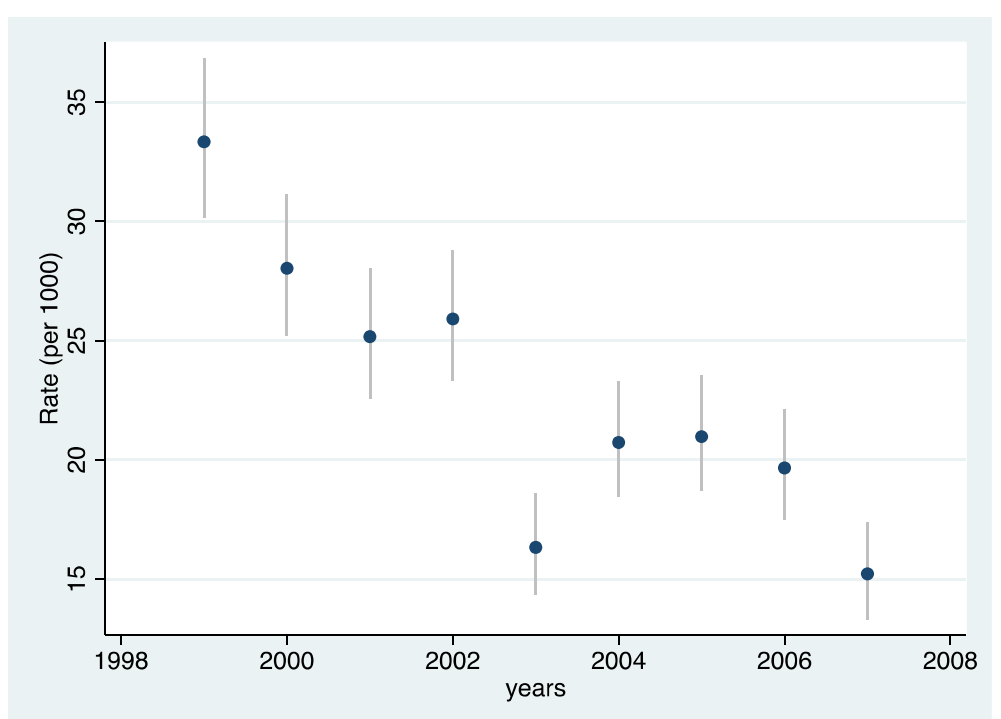

Figure 2 Under five mortality rates (per 1,000 person-years) trends in the Rufiji Health and Demographic Surveillance System (RHDSS), Tanzania, 1999-2007. 
Table 2 Under-five causes of death rates (per 1,000 person-year) by period in the Rufiji Health and Demographic Surveillance System (RHDSS), Tanzania, 1999-2007

\begin{tabular}{|c|c|c|c|c|c|c|}
\hline \multirow[t]{2}{*}{ Cause of death } & \multicolumn{2}{|c|}{ 1999-2002 } & \multicolumn{2}{|c|}{ 2003-2007 } & \multicolumn{2}{|c|}{ Overall } \\
\hline & $\mathbf{N}$ & Death rates & $\mathbf{N}$ & Death rates & $N$ & Death rates \\
\hline Malaria and fever & 623 & 12.5 & 540 & 7.8 & 1163 & 9.8 \\
\hline Pneumonia & 200 & 4.0 & 192 & 2.8 & 392 & 3.3 \\
\hline Diarrhoeal diseases & 39 & 0.8 & 14 & 0.2 & 53 & 0.5 \\
\hline Anaemia & 44 & 0.9 & 110 & 1.6 & 154 & 1.3 \\
\hline Malnutrition & 86 & 1.7 & 63 & 0.9 & 149 & 1.3 \\
\hline Birth Injuries/Asphyxia & 59 & 1.2 & 104 & 1.5 & 163 & 1.3 \\
\hline Prematurity/LBW & 105 & 2.1 & 131 & 1.9 & 236 & 2.0 \\
\hline Congenital abnormalities & 31 & 0.6 & 14 & 0.2 & 46 & 0.4 \\
\hline Other perinatal & 105 & 2.1 & 37 & 0.5 & 142 & 1.2 \\
\hline Other & 107 & 2.2 & 87 & 1.3 & 194 & 1.6 \\
\hline Total & 1399 & 28.1 & 1292 & 18.6 & 2691 & 22.6 \\
\hline Person-year & & 49762.8 & & 69419.3 & & 119219.4 \\
\hline
\end{tabular}

Rate $=$ number of death due to cause $\mathrm{x} /$ person-year.

Bold $=$ significant differences $(p<0.05)$ (Two-sided chi-square test).

Source: Database of Rufiji HDSS, 2012.

each cause is calculated by dividing the contribution of each cause by the change due to all causes. The major cause contributor to U5MR decline is presumptive malaria-related mortality, which explains half of the period differential in life expectancy. Other causes contributed to a relatively small proportion, perinatal causes (16.5\%), pneumonia (13.1\%), malnutrition (8.7\%), diarrhoeal diseases (6.1\%), congenital abnormalities (4.5\%) and PLBW (2.2\%). However, anaemia and BIA are higher over the 2003-2007 period, thus contributing to increasing mortality by 7.2 and $3.3 \%$ respectively.

In summary, between 1999-2002 and 2003-2007, presumptive malaria remained the major cause contributor to U5MR decline, $49.9 \%$, while all perinatal causes contributed only $19.9 \%$. While the presumptive malaria mortality rate significantly declined, it remains the leading cause of death followed by pneumonia. PLBW remained the leading cause of death for the neonates followed by the emergence of BIA (Figure 3).

\section{Discussion}

Although important insights emerge from this analysis, results must be interpreted with caution owing to data limitations. Findings on cause of deaths trends in the RHDSS could be validated only (1) by supposing that the data collection protocol and diagnostic method of

Table 3 Contribution of under-five cause-specific death rates under-five in the Rufiji Health and Demographic Surveillance System (RHDSS), Tanzania, Arriaga's method

\begin{tabular}{|c|c|c|c|c|c|}
\hline Cause of death & $\begin{array}{c}\text { 1999-2002 } \\
\text { death rates }\end{array}$ & $\begin{array}{l}2003-2007 \\
\text { death rates }\end{array}$ & $\begin{array}{l}\text { Difference in } \\
\text { death rates }\end{array}$ & Proportionate contribution & Contribution \\
\hline Malaria/fever & 12.5 & 7.8 & 4.7 & 49.9 & 0.8798 \\
\hline Pneumonia & 4.0 & 2.8 & 1.2 & 13.1 & 0.2311 \\
\hline Diarrhoeal diseases & 0.8 & 0.2 & 0.6 & 6.1 & 0.1080 \\
\hline Anaemia & 0.9 & 1.6 & -0.7 & -7.2 & -0.1275 \\
\hline Malnutrition & 1.7 & 0.9 & 0.8 & 8.7 & 0.1538 \\
\hline Birth injuries/Asphyxia & 1.2 & 1.5 & -0.3 & -3.3 & -0.0587 \\
\hline Prematurity/LBW & 2.1 & 1.9 & 0.2 & 2.2 & 0.0393 \\
\hline Congenital abnormalities & 0.6 & 0.2 & 0.4 & 4.5 & 0.0788 \\
\hline Other perinatal & 2.1 & 0.5 & 1.6 & 16.5 & 0.2905 \\
\hline Other causes & 2.2 & 1.3 & 0.9 & 9.5 & 0.1670 \\
\hline All causes & 28.1 & 18.6 & 9.5 & 100.0 & 0.0002 \\
\hline
\end{tabular}

Source: Database of Rufiji HDSS, 2012. 


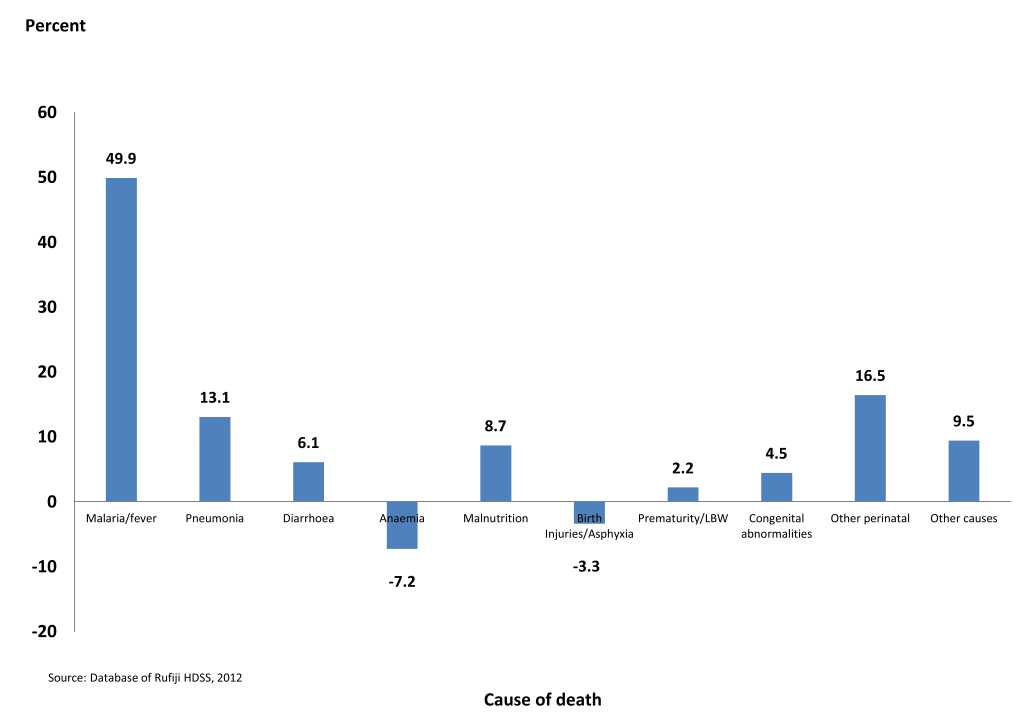

Figure 3 Proportionate contribution of under-five specific cause of death to the total change in life expectancy between birth and age five in the Rufiji Health and Demographic Surveillance System (RHDSS), Tanzania, 1999-2007.

cause of death remained unchanged over the reference period and (2) by accepting the proportional redistribution method of unknown causes. The VA technique is widely used to ascribe childhood causes of death. This method is however known to be reliable for diagnosing only certain causes of deaths, such as measles, whooping cough, cholera, injuries and violence, while less so for delineating causes of associated with different febrile illnesses [27-30]. Caution must, therefore, be directed to ascribing to VA methods an ability to distinguish malaria from other causes of febrile illnesses that are common in the African context [31]. Although most of HDSS in sub-Saharan Africa are using VA methods with forms, procedures, and definitions that have not changed [32], VA data are compiled by field interviewers and medical VA readers. During the course of the project, different people rotated into these positions. Such subtle staffing changes may have introduced variation in the classification of causes of death over time. However, observers posit that such changes have a little impact on cause of death as diagnosed by physicians [33]. VA data also can be adjusted to allow for some of the misclassification biases [29] and for sensitivity and specificity in malaria mortality but this requires information on parasite prevalence also [32].

The proportion of unknown causes may also have an impact in the cause of deaths distribution. In 2002-2007, this proportion was however low in the RHDSS (19\%) compared to Ifakara HDSS (31\%), another HDSS in Tanzania [34]. The proportional redistribution method keeps unchanged cause of deaths trends over time. It allocates however a significant number to the most representative categories of causes of deaths. Thus, the proportionate contribution of presumptive malaria on U5MR decline would be at least $50 \%$ in RHDSS.

More recently, researchers have developed and applied standardized computer-based algorithm to assign causes of deaths using VA data. These probabilistic models have the advantage of being more internally consistent than physician generated causation estimates but mechanization of inference may lack essential subtlety and nuance [19,35-38]. These methods do not allocate specific cause for each death. They also produce undetermined causes, which should be included in the analysis [39]. This paper did not use such methods to compare with causes of deaths diagnosed by physicians. However, standardized computerbased algorithm methods can be useful to assess neonatal cause of deaths which remain more complicated to diagnose by physician [40].

The research legacy associated with the Rufiji study area may also have had an impact on results. The RHDSS, among other studies has been used as a platform of research on malaria. This focus on malaria and related pharmaceutical trials could influence the climate of diagnosis that physicians apply to causes of deaths. Due to their specialization, developed in the course of other studies, participating physicians may weight causes more heavily toward malaria than would be the case among physicians who lack this specialization [28,37].

The combining of malaria and fever (presumptive malaria) is related to the changes in the percent of children deaths attributed to fever or malaria between 1999-2002 and 2003-2007. That changes in the diagnose VA could be related, in part, to the concomitant introduction in most primary health care facilities of malaria rapid diagnostic tests (mRDTs) [41], the absence of any other new 
modality that would reduce mortality related to febrile illness [42] and to a large proportion of malaria deaths being properly recoded by the RHDSS.

These limitations, while important to note, are less likely to apply to inference related to long-term trend data than to simple cross-sectional studies. The RHDSS data, though flawed, are standardized over time. Changing compositions of estimated cause of death are more likely to arise from actual shifts in mortality risk than from shifts in any particular source of bias.

Over the past two decades, successive DHS in subSaharan Africa have documented a rapid decline of U5MR particularly in rural areas. However, these surveys do not provide the specific causes of deaths. Thus, HDSS in rural settings remain the main source providing accurate information on trends and causes of deaths in delimited area $[31,43]$. Results revealed that underfive mortality trends in the RHDSS were similar to the overall rural area in Tanzania [7]. If this trend is sustained, RHDSS and Tanzania as a whole [44] will be a locality that achieves the MDG4 target.

Second, three-quarters of the children under-five who died experienced one of only six causes (presumptive malaria, pneumonia, diarrheal diseases, malnutrition, PLBW and congenital abnormalities) as described for populations elsewhere in Africa [8-11]. Though all of these causes are in the process of decline, they remain the major killers of children in RHDSS. Nonetheless, their declining importance has dominated the process of U5MR decline in the RHDSS during the last decade.

Despite its high contribution to the U5MR decline, these results corroborate with the previous findings that malaria remains the leading cause of death among children in sub-Saharan Africa [45]. However, improvements in malaria prevention and care may explain why the decline in malaria-related mortality decline predominates as the cause contributing most to this progress. The successful introduction of preventive measures, particularly the insecticide-treated mosquito net [46-51] and more recent expansion of the availability of the mRDT [52,53] have had their intended impact. The introduction of mRDT has allowed immediate treatment of patients through efficient and low-cost drugs (Artemisinin-based combination therapy, ACT) [51,54]. Since March 2007, the ACT was introduced as first-line treatment for uncomplicated malaria and was provided free of charge through all fixed health facilities in Rufiji district [55]. Results from this study were also comparables to the Niakhar HDSS in Senegal [56] indicating that malaria-attributable mortality in under-5 children decreased from 13.5/1,000 during 1992-1999 to 2.2/1,000 in 2010 accelerating the achievement of MDG 4 in that rural area. That suggests that effective control of malaria can be sufficient to allow poor rural areas of Africa to meet MDG4.
Findings show that the contribution of anaemia to increase mortality goes against expected results regarding the contribution of malaria in that area of very high malarial transmission [57,58]. In rural Kenya, malaria and/or anaemia accounted for the greatest increases in U5MR in 2008-2009 due to stock-outs of essential anti-malarial drugs [59]. In the RHDSS, the slight increased of anaemia mortality rates between 2003 and 2007 could be related to other causes of deaths. Malaria alone is not the cause of anaemia and other possibilities include nutritional anaemia and hookworm infection [7].

Despite its contribution to mortality decrease, pneumonia remains one of most serious killers of young Tanzanians [7] as well as sub-Saharan African children elsewhere $[9,60]$. Mortality attributable to pneumonia has been reduced by third in the RHDSS over time probably due to reduction of the prevalence, the early diagnosis and the availability of treatment (antibiotics) with the successful introduction of the program known as the Integrated Management of Childhood Illness (IMCI) [61]. Most of the leading risk factors contributing to pneumonia incidence notably, lack of exclusive breastfeeding, malnutrition, indoor air pollution, low birth weight, crowding and lack of measles immunization [60] have been improved in the RHDSS over time.

Neonatal mortality remained high with only slight decline in the RHDSS and Tanzania in general $[7,62,63]$. PLBW and BIA remain the leading neonatal causes of deaths in the RHDSS as noted elsewhere in Africa [9,11].

\section{Conclusion}

The results of this study suggest that several causes have contributed to rapid decline in U5MR in RHDSS. Presumptive malaria-related mortality was however the predominant contributor to the U5MR decline over the study period. Yet, despite this progress, presumptive malaria remains as a tragically high source of risk of mortality to young children. Thus, findings attest to the need (1) for renewed malaria control efforts and delivery of IMCI and (2) for improvement in the clinical management of complications of childbirth and preterm birth in commitment to strengthening maternal and newborn health to promote improved case of neonates. But the remaining challenge represented by malaria demonstrates that achieving MDG 4 requires continued attention to expanding efforts to reduce malaria related mortality.

\section{Abbreviations}

ACT: Artemisinin-based combination therapy; BIA: Birth injuries and asphyxia; DHS: Demographic and Health Surveys; HDSS: Health and Demographic Surveillance System; IMCI: Integrated Management of Childhood IIIness; MDG: Millennium Development Goal; PLBW: Prematurity and low birth weight; U5MR: Under-five mortality rates; RHDSS: Rufiji Health and Demographic Surveillance System; VA: Verbal autopsy. 


\section{Competing interests}

The authors declare that they have no competing interests.

\section{Authors' contributions}

AMK, SH and JFP conceived and designed the study. MS/FL prepared the dataset. AMK led the data analysis. AMK, JFP, RN, DS drafted the manuscript. All co-authors assisted the interpretation of results and made critical revisions of the manuscript. All authors read and approved the final manuscript.

\section{Acknowledgments}

This research was funded by grants from the Doris Duke Charitable Foundation funded Africa Health Initiative and the British charity Comic Relief. The Ifakara Health Institute is a participating member of the International Network of field sites with continuous Demographic Evaluation of Populations and Their Health in developing countries (INDEPTH-NETWORK) The authors gratefully acknowledge the contribution of INDEPTH for the verbal autopsy tools used for the present analysis.

\section{Author details}

1 Mailman School of Public Health, Columbia University, 60 Haven Avenue, New York 10032, USA. ${ }^{2}$ Ifakara Health Institute, PO Box 78373, Dar-Es-Salaam, Tanzania. ${ }^{3}$ Swiss Tropical and Public Health Institute, University of Basel, Socinstrasse 57, CH-4002 Basel, Switzerland.

\section{Received: 23 October 2013 Accepted: 3 May 2014}

Published: 10 May 2014

\section{References}

1. World Bank: The Millennium Development Goals for Health: Rising to the Challenges. Washington: World Bank; 2004.

2. United Nations: The Millenniums Development Goals Report, 2012. New York United Nations; 2012.

3. Lozano R, Wang H, Foreman KJ, Rajaratnam JK, Naghavi M, Marcus JR, Dwyer-Lindgren L, Lofgren KT, Phillips D, Atkinson C, Lopez AD, Murray CJL: Progress towards Millennium Development Goals 4 and 5 on maternal and child mortality: an updated systematic analysis. Lancet 2011, 378:1139-1165.

4. Tanzania: Demographic and Health Survey 1991/2, Dar es Salaam: National Bureau of Statistics. Calverton: Macro international Inc; 1992.

5. Tanzania: Demographic and Health Survey 1996, Dar es Salaam: National Bureau of Statistics. Calverton: Macro international Inc; 1997.

6. Tanzania: Demographic and Health Survey 2004/5, Dar es Salaam: National Bureau of Statistics. Calverton: Macro international Inc; 2005.

7. Tanzania: Demographic and Health Survey 2010, Dar es Salaam: National Bureau of Statistics. Calverton: Macro International Inc; 2011.

8. Bryce J, Boschi-Pinto C, Shibuya K, Black RE, and the WHO Child Health Epidemiology Reference Group: WHO estimates of the causes of death in children. Lancet 2005, 365:1147-1152.

9. Black RE, Cousens S, Johnson H, Lawn JE, Rudan I, Bassani DG, Jha P, Campbell H, Walker CF, Cibulskis R, Eisele T, Liu L, Mathers C, Child Health Epidemiology Reference Group of WHO and UNICEF: Global, regional and national causes of child mortality, 2008. Lancet 2010, 375:1969-1987.

10. Hope LJ, Liu L, Walker CF, Black RE: Estimating the distribution of causes of child deaths in high mortality countries with incomplete death certification. Int J Epidemiol 2010, 39:1103-1114.

11. Liu L, Hope L, Cousens S, Perin J, Scott S, Lawn JE, Rudan I, Campbell H, Cibulskis R, Li M, Mathers C, Black RE, for the Child Health Epidemiology Reference Group of WHO and UNICEF: Global, regional, and national causes of child mortality: an updated systematic analysis for 2010 with time trends since 2000. Lancet 2012, 379:2151-2161.

12. INDEPTH Network: Population and Health in Developing Countries. Ottawa: International Development Research Centre; 2002:339.

13. Mwageni E, Momburi D, Juma Z, Irema M, Masanja H, and the TEHIP and AMMP Teams: Rufiji DSS. In INDEPTH Monograph Series: Population and Health in Developing Countries. Ottawa: 1, IDRC Press; 2002.

14. de Savigny D, Mayombana C, Mwageni E, Masanja H, Minhaj A, Mkilindi Y, Mbuya C, Kasale H, Reid G: Care-seeking patterns for fatal malaria in Tanzania. Malar J 2004, 3:27.

15. Mrema S, Shamte A, Selemani M, Masanja H: The influence of weather on mortality in rural Tanzania: a time-series analysis 1999-2010. Glob Health Action 2012, 5:33-43.
16. Ifakara Health Institute: 2000-2009 Health and Demographic Surveillance System. Dar es Salaam: Ifakara Health Institute; 2010:30.

17. World Health Organization: International Statistical Classification of Diseases and Related Health Problems. Geneva: World Health Organization: Tenth Revision; 1993

18. Shabani J, Lutambi AM, Mwakalinga V, Masanja H: Clustering of under-five mortality in Rufiji health and demographic surveillance system in rural Tanzania. Glob Health Action 2010, 3. doi:10.3402/gha.v3i0.5264.

19. Liu L, Li Q, Lee RA, Friberg IK, Perin J, Walker N, Black RE: Trends in causes of death among children under 5 in Bangladesh, 1993-2004: an exercise applying a standardized computer algorithm to assign causes of death using verbal autopsy data. Popul Health Metrics 2011, 9:43.

20. Narh-Bana SA, Chirwa TF, Mwanyangala MA, Nathan R: Adult deaths and the future: a cause-specific analysis of adult deaths from a longitudinal study in rural Tanzania 2003-2007. Trop Med Int Health 2012, 17:1396-1404.

21. Waltisperger D, Meslé F: Economic crisis and mortality: the case of Antananarivo, 1976-2000. Population 2005, 3:243-275.

22. Naghavi M: Algorithms for enhancing public health utility of national causes-of-death data. Population Health Metrics 2010, 8:9.

23. Abdullah S, Adazu K, Masanja H, Diallo D, Hodgson A, Ilboudo-Sanogo E, Nhacolo A, Owusu-Agyei S, Thompson R, Smith T, Binka FN: Patterns of age-specific mortality in children in endemic areas of sub-Saharan Africa. Am J Trop Med Hyg 2007, 77(Suppl 6):99-105.

24. Chiang CL: The Life Table and Its Applications. Florida: Malabar; 1984:316.

25. Arriaga E: Measuring and explaining the change in life expectancies. Demography 1984, 21:83-96.

26. Stata Corporation: Stata Statistical Software: Release 12. College Station, TX: Stata Press; 2012.

27. Kalter HD, Gray RH, Black RE, Gultiano SA: Validation of postmortem interviews to ascertain selected causes of death in children. Int $J$ Epidemiol 1990, 19:380-386.

28. Snow RW, Armstrong JR, Forster D, Winstanley MT, Marsh VM, Newton CR, Waruiru C, Mwangi I, Winstanley PA, Marsh K: Childhood deaths in Africa: uses and limitations of verbal autopsies. Lancet 1992, 340:351-355.

29. Chandramohan D, Setel P, Quigley M: Effect of misclassification of causes of death in verbal autopsy: can it be adjusted? Int J Epidemiol 2001, 30:509-514

30. Setel PW, Whiting DR, Hemed Y, Chandramohan D, Wolfson LJ, Alberti KGMM, Lopez AD: Validity of verbal autopsy procedures for determining cause of death in Tanzania. Trop Med Int Health 2006, 11:681-696.

31. Ye Y, Kyobutungi C, Ogutu B, Villegas L, Diallo D, Tinto H, Oduro A, Sankoh O: Malaria mortality estimates: need for agreeable approach. Trop Med Int Health 2013, 18:219-221.

32. Korenromp EL, Williams BG, Gouws E, Dye C, Snow R: Measurement of trends in childhood malaria mortality in Africa: an assessment of progress toward targets based on verbal autopsy. Lancet Inf Dis 2003, 3:349-358.

33. Duthé G, Faye SHD, Guyavarch E, Arduin P, Kanté AM, Diallo A, Laurent R, Marra A, Pison G: [Change of protocol in verbal autopsy method and measure of malaria mortality in Senegalese rural area] (Changement de protocole dans la méthode d'autopsie verbale et mesure de la mortalité palustre en milieu rural sénégalais). Bull Soc Path Exot 2010, 103:327-332.

34. Mwanyangala MA, Urassa HM, Rutashobya JC, Mahutanga CC, Lutambi AM, Malit DV, Masanja HM, Abdulla SK, Lema RN: Verbal autopsy completion rate and factors associated with undetermined cause of death in a rural resource-poor setting of Tanzania. Popul Health Metrics 2011, 9:41.

35. Fantahun M, Fottrell E, Berhane $Y$, Wall S, Högberg U, Byass P: Assessing a new approach to verbal autopsy interpretation in a rural Ethiopian community: the InterVA model. Bull World Health Organ 2006, 84:204-210.

36. Byass P, Fottrell E, Huong DL, Berhane Y, Corrah T, Kahn K, Muhe L, Van DD: Refining a probabilistic model for interpreting verbal autopsy data. Scand J Public Health 2006, 34:26-31.

37. Lozano R, Lopez AD, Atkinson C, Naghavi M, Flaxman AD, Murray CJ, and the Population Health Metrics Research Consortium (PHMRC): Performance of physician-certified verbal autopsies: multisite validation study using clinical diagnostic gold standards. Popul Health Metrics Health 2011, 9:32.

38. Byass P, Chandramohan D, Clark SJ, D'Ambruoso L, Fottrell E, Graham WJ, Herbst AJ, Hodgson A, Hounton S, Kahn K, Krishnan A, Leitao J, Odhiambo F, Sankoh OA, Tollman SM: Strengthening standardised interpretation of verbal autopsy data: the new InterVA-4 tool. Glob Health Action 2012, 5:1-8.

39. Ramroth H, Lorenz E, Rankin JC, Fottrell E, Ye' M, Neuhann F, Ssennono M, Sie' A, Byass P, Becher $\mathrm{H}$ : Cause of death distribution with InterVA and 
physician coding in a rural area of Burkina Faso. Trop Med Int Health 2012, 17:904-913.

40. Thatte N, Kalter HD, Baqui AH, Williams EM, Darmstadt GL: Ascertaining causes of neonatal deaths using verbal autopsy: current methods and challenges. J Perinat 2009, 29:187-194.

41. National Malaria Control Programme: National Guidelines for Malaria Diagnosis and Treatment. Dar es Salaam: Ministry of Health and Social Welfare and National Malaria Control Programme; 2006.

42. McMorrow ML, Masanja MI, Abdulla SMK, Kahigwa E, Kachur SP: Challenges in routine implementation and quality control of rapid diagnostic tests for malaria-Rufiji District, Tanzania. Am J Trop Med Hyg 2008, 79:385-390.

43. Fottrell E, Kahn K, Tollman S, Byass P: Probabilistic methods for verbal autopsy interpretation: InterVA robustness in relation to variations in a priori probabilities. PLoS One 2011, 6:e27200. National Malaria Control Programme.

44. Masanja H, de Savigny D, Smithson P, Schellenberg J, John T, Mbuya C, Upunda G, Boerma T, Victora C, Smith T, Mshinda H: Child survival gains in Tanzania: analysis of data from demographic and health surveys. Lancet 2008, 371:1276-1283.

45. WHO: Guidelines for the Treatment of Malaria. Secondth edition. Geneva: World Health Organization; 2010.

46. Murray CJL, Rosenfeld LC, Lim SS, Andrews KG, Foreman KJ, Haring D, Fullman N, Naghavi M, Lozano R, Lopez AD: Global malaria mortality between 1980 and 2010: a systematic analysis. Lancet 2012, 379:413-431.

47. Lengeler C: Insecticide-treated nets for malaria control: real gains. Bull World Health Organ 2004, 82:84.

48. Schellenberg Armstrong JRM, Abdulla S, Nathan R, Mukasa O, Marchant TJ, Kikumbih N, Mushi AK, Mponda H, Minja H, Mshinda H, Tanner M, Lengeler C: Effect of large-scale social marketing of insecticide-treated nets on child survival in rural Tanzania. Lancet 2001, 357:1241-1247.

49. Binka FN, Hodgson A, Adjuik M, Smith T: Mortality in a seven-and-a-half-year follow up of a trial of insecticide-treated mosquito nets in Ghana. Trans $R$ Soc Trop Med Hyg 2002, 96:97-99.

50. Steketee RW, Campbell CC: Impact of national malaria control scale-up programmes in Africa: magnitude and attribution of effects. Malar J 2010, 9:299.

51. Trape JF, Tall A, Diagne N, Ndiath O, Ly AB, Faye J, Dieye-Ba F, Roucher C, Bouganali C, Badiane A, Sarr FD, Mazenot C, Touré-Baldé A, Raoult D, Druilhe P, Mercereau-Puijalon O, Rogier C, Sokhna C: Malaria morbidity and pyrethroid resistance after the introduction of insecticide-treated bednets and artemisinin-based combinatin terapies: a longitudinal study. Lancet Inf Dis 2011, 11:925-932.

52. Mubi M, Janson A, Warsame M, Mårtensson A, Källander K, Petzold MG Ngasala B, Maganga G, Gustafsson LL, Massele A, Tomson G, Premji Z, Björkman A: Malaria rapid testing by community health workers is effective and safe for targeting malaria treatment: randomised cross-over trial in Tanzania. PLoS One 2011, 6:e19753.

53. D'Acremont V, Lengeler C, Mshinda H, Mtasiwa D, Tanner M, Genton B: Time to move from presumptive malaria treatment to laboratory-confirmed diagnosis and treatment in African children with fever. PLoS Med 2009, 6:e252.

54. WHO: World Malaria Report. Geneva: World Health Organization; 2010.

55. Huho BJ, Killeen GF, Ferguson HM, Tami A, Lengeler C, Charlwood JD, Kihonda A, Kihonda J, Kachur SP, Smith TA, Abdulla SM: Artemisinin-based combination therapy does not measurably reduce human infectiousness to vectors in a setting of intense malaria transmission. Malar J 2012, 11:118.

56. Trape JF, Sauvage C, Ndiaye O, Douillot L, Marra A, Diallo A, Cisse B, Greenwood B, Milligan P, Sokhna C, Molez JF: New malaria-control policies and child mortality in Senegal: reaching Millennium Development Goal 4. J Inf Dis 2012, 205:672-679.

57. Menendez C, Fleming AF, Alonso PL: Malaria-related anaemia. Parasitol Today 2000, 16:469-476.

58. Schellenberg D, Menendez C, Kahigwa E, Aponte J, Vidal J, Tanner M, Mshinda $\mathrm{H}$, Alonso P: Intermittent treatment for malaria and anaemia control at time of routine vaccinations in Tanzanian infants: a randomised, placebocontrolled trial. Lancet 2001, 357:1471-1477.

59. Hamel MJ, Adazu K, Obor D, Sewe M, Vulule J, John WM, Slutsker L, Feikin DR, Kayla FL: A reversal in reductions of child mortality in Western Kenya, 2003-2009. Am J Trop Med Hyg 2011, 85:597-605.

60. Rudan I, Boschi-Pinto C, Biloglav Z, Mulholland K, Campbell H: Epidemiology and etiology of childhood pneumonia. Bull World Health Organ 2008, 86:408.
61. Schellenberg Armstrong JRM, Adam T, Mshinda H, Masanja H, Kabadi G, Mukasa O, John T, Charles S, Nathan R, Wilczynska K, Mgalula L, Mbuya C, Mswia R, Manzi F, de Savigny D, Schellenberg D, Victora C: Effectiveness and cost of facility-based Integrated Management of Childhood IIIness (IMCI) in Tanzania. Lancet 2004, 364:1583-1594.

62. Ajaari J, Masanja H, Weiner R, Abokyi SA, Owusu-Agyei S: Impact of place of delivery on neonatal mortality in rural Tanzania. Int J MCH AIDS 2012, $1: 49-59$.

63. Nathan R, Mwanyangala MA: Survival of neonates in rural Southern Tanzania: does place of delivery or continuum of care matter? BMC Preg Childbirth 2012, 12:18.

doi:10.1186/1475-2875-13-180

Cite this article as: Kanté et al:: The contribution of reduction in malaria as a cause of rapid decline of under-five mortality: evidence from the Rufiji Health and Demographic Surveillance System (HDSS) in rural Tanzania. Malaria Journal 2014 13:180.

\section{Submit your next manuscript to BioMed Central and take full advantage of:}

- Convenient online submission

- Thorough peer review

- No space constraints or color figure charges

- Immediate publication on acceptance

- Inclusion in PubMed, CAS, Scopus and Google Scholar

- Research which is freely available for redistribution 